\title{
8
}
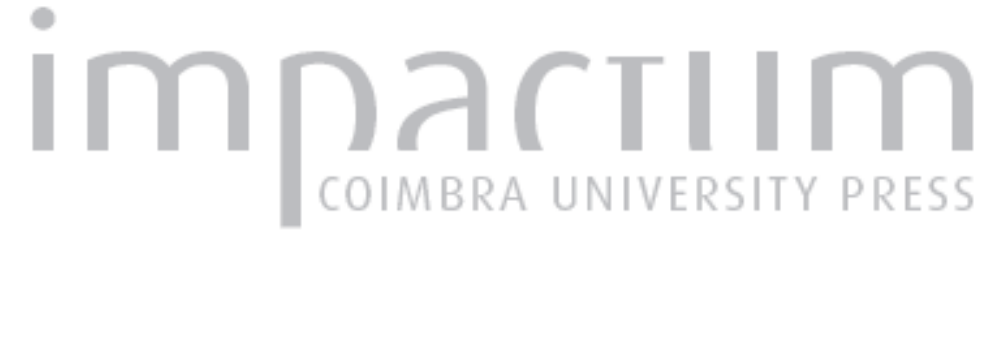

\section{Wells e Portugal: encontros e desencontros}

Autor(es): Mota, José Manuel

Publicado por: Imprensa da Universidade de Coimbra

URL persistente:

URI:http://hdl.handle.net/10316.2/35506

DOI:

DOI:http://dx.doi.org/10.14195/0870-4112_11_9

Accessed : $\quad$ 26-Apr-2023 12:22:51

A navegação consulta e descarregamento dos títulos inseridos nas Bibliotecas Digitais UC Digitalis, UC Pombalina e UC Impactum, pressupõem a aceitação plena e sem reservas dos Termos e Condições de Uso destas Bibliotecas Digitais, disponíveis em https://digitalis.uc.pt/pt-pt/termos.

Conforme exposto nos referidos Termos e Condições de Uso, o descarregamento de títulos de acesso restrito requer uma licença válida de autorização devendo o utilizador aceder ao(s) documento(s) a partir de um endereço de IP da instituição detentora da supramencionada licença.

Ao utilizador é apenas permitido o descarregamento para uso pessoal, pelo que o emprego do(s) título(s) descarregado(s) para outro fim, designadamente comercial, carece de autorização do respetivo autor ou editor da obra.

Na medida em que todas as obras da UC Digitalis se encontram protegidas pelo Código do Direito de Autor e Direitos Conexos e demais legislação aplicável, toda a cópia, parcial ou total, deste documento, nos casos em que é legalmente admitida, deverá conter ou fazer-se acompanhar por este aviso.

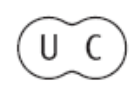




\section{ESTÉTICA E POLÍTICA}

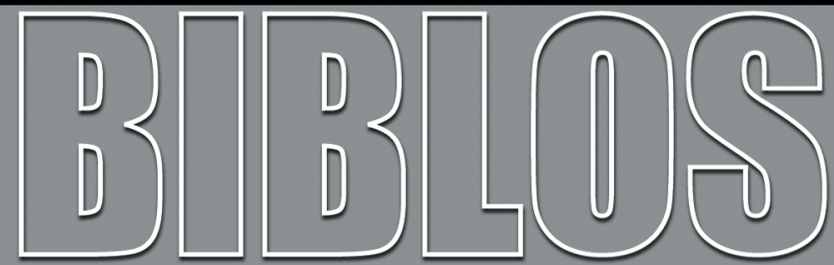

REVISTA DA FACULDADE DE LETRAS UNIVERSIDADE DE COIMBRA 
Biblos, n. s. XI (2013) 251-261

DOI: http://dx.doi.org/10.14195/0870-4112_11_9

$\dagger$ José Manuel Mota

Faculdade de Letras da UC

\section{WELLS E PORTUGAL: ENCONTROS E DESENCONTROS}

Wet or fine, the air of Portugal has a natural happiness in it, and the people of the country should be as happy and prosperous as any people in the world.

H.G. WELLS

A Year of Prophesying, London: T. Fish Unwin, 1924, 128.

De facto, frequentemente menosprezado (o escasso número de obras críticas sobre ele para isso aponta) e quase apenas identificado como o criador de universos de ficção científica de qualidade estética discutível, o nome de Wells está ligado, em Portugal, essencialmente à escrita da história.

MARIA LEONOR FERNANDES

Uma Conspiração para o Futuro: o Ensaísmo Político e Educacional em H.G. Wells, Universidade Nova de Lisboa, 1993

0. Não sei ao certo quantas vezes veio Wells a Portugal; sei que esteve cá em 1924 e ficou hospedado no Estoril, no Hotel Miramar. Nesse mesmo ano publicou uma colecção de artigos a que deu o título de A Year of Prophesying. Da sua estadia entre nós resultou um breve ensaio a que chamou "Portugal and Prosperity. The blessedness of being a little nation". Nele Wells louva o nosso clima - e lamenta o nosso óbvio subdesenvolvimento. E, sublinhava, o país até tinha condições - riquezas naturais (urânio!), um magnífico porto, um império colonial cheio

${ }^{1}$ Conferência “de despedida" oferecida pelo Doutor José Manuel Mota aos colegas em vésperas da sua aposentação. 
de potencialidades; mas a administração é péssima, e há uma terrível falta de senso prático. Para Wells tudo está como está porque os portugueses continuam agarrados a ideias ultrapassadas quanto à soberania nacional (por exemplo, a de terem uma moeda própria). Para o aguerrido campeão do Estado Mundial, a solução para o nosso atraso passava pela integração numa associação de Estados em consonância política, financeira e económica ("a combine of States, acting together politically, financially, and economically"): uma espécie de pequena CEE.

O que é interessante é que, no meio da sua justificação, Wells diz o seguinte: "a little country like this, with an unstable currency, cannot keep its popular education up to date; there is not a sufficient reading public therefore to sustain an authoritative Press and literature of political criticism" (Wells 1924, 130). Isto é, um país culturalmente subdesenvolvido é também politicamente incompetente, por falta duma educação democrática e cívica. Ou, se quisermos, uma educação tout court. Não só a educação de que falava Wells, mas sequer a mera alfabetização.

Até aqui, se formos a ver bem, nada de novo: estamos a falar dum país que, entre 1910 e 1940, para uma população de menos de seis milhões de habitantes, baixou a taxa de analfabetismo de $70 \%$ para $50 \%$. Num país destes, onde apenas uma magra minoria poderia ler as novelas fantástico-científicas de Wells, para já não falar da ficção realista ou do ensaio, quem é que o ia ler? E quem é que o ia publicar?

1. Em 1899 a filial brasileira da livraria Garnier publicou A Machina de Explorar o Tempo de H.G. Wells. O título português, decalcado na versão de Henry-D. Davray, faz supor que a tradução foi feita a partir do francês. E se formos comparar o texto, o decalque transparece.

A partir de 1899 a mesma editora publicou Doze Histórias e Um Sonho, A Guerra dos Mundos, A Ilha do Doutor Moreau, Os Primeiros Homens na Lua, O Homem Invisivel e, num volume único, as duas novelas longas Uma História dos Tempos Futuros e Narrações da Idade da Pedra. Reedições foram sendo feitas até aos anos 20. Alguns destes volumes terão aparecido em Portugal (eu consultei vários na Biblioteca Nacional de Lisboa); mas creio que seria mais provável, e mais fácil ao português ilustrado e interessado, e que não dominasse o inglês, procurar as traduções francesas.

Enquanto no Brasil se traduzia do francês, outras versões apareceram simultaneamente em Portugal. The First Men in the Moon apa- 
receu com o título Os Exploradores da Lua; este, e as Narrativas do Tempo Primitivo ("A Story of the Stone Age"), saíram em 1902, Uma História dos Tempos Futuros ("A Story of the Days To Come") em 1903, O Homem Invisivel (The Invisible Man) em 1905 (em folhetim n'O Primeiro de Janeiro) e O Alimento dos Deuses (The Food of the Gods) em1908. (edições muito próximas das originais inglesas).

Depois, o silêncio. Mais nenhum texto de ficção wellsiano veio a ser publicado até 1934, quando surgiram traduções originais de A Guerra dos Mundos e de O Homem Invisivel. Em 1936 The Time Machine foi publicada numa edição popular pela Livraria Civilização com o singular título de Viagem à Esfinge Branca.

Tirando as traduções do princípio do século de alguma ficção científica o único texto de Wells traduzido em Portugal até aos anos trinta foi What Is Coming: a Forecast of Things after the War (1916), com o título A Nova Europa. É uma colecção de artigos sobre a política do tempo, entre nós publicado no Porto em 1919. A Grande Guerra provocou uma profunda divisão entre os portugueses; à data em que o livro saiu em Portugal tínhamos tido o Sidonismo, a Monarquia do Norte, a batalha do rio Lys; o livro terá despertado o interesse natural na nossa república de tão curta e atribulada história.

O facto de A Nova Europa ter sido publicado numa colecção chamada "Bibliotheca de Educação Intellectual" é, porém, significativo: a palavra "educação" é uma palavra-chave nas relações entre Wells e Portugal, e a principal questão por ele apontada ao falar de Portugal e da sua prosperidade é precisamente a questão da educação.

2. Em países como Portugal - e o Brasil - com um subdesenvolvimento cultural endémico, foi o Wells educador, pedagogo, que mais interessou a intelectualidade; e é aqui, mesmo se a sua presença não é grande, que vamos encontrar uma resposta de intelectuais portugueses às suas ideias.

Em 1922 António Sérgio escreveu o que é provavelmente o primeiro exemplo duma reacção da intelectualidade portuguesa ao pensamento wellsiano. O texto "Divagações pedagógicas a propósito de um livro de Wells" é uma espécie de recensão alargada a The Undying Fire (1919). Sérgio leu o livro em francês, e alarga-se na discussão dos modelos pedagógicos que são apresentados e confrontados pelo autor inglês. (Sérgio 1974, 167). 
The Undying Fire é, sob a forma duma imitação do livro de Job, um diálogo entre um professor doente e três outras pessoas que o vêm ver. O tema é o modelo de educação a seguir, numa época atribulada como era o sombrio início do pós-guerra. A personagem do professor, Job Huss (i.e., Job, da terra de Hus, segundo o diálogo sapiencial bíblico), é uma figura inspirada em Frederick William Sanderson, o reitor da escola de Oundle, frequentada pelos filhos de Wells.

Sérgio tinha em comum com Wells a paixão da educação, e a paixão do socialismo (ainda que para ele o "socialismo" fosse antes de tudo o movimento cooperativo, "a Sociedade fraterna da cooperação", 169). O racionalista António Sérgio foi talvez antes de mais um polemista; Salgado Júnior vê-o como promotor duma "pedagogia de self-government, duma educação cívica de consciência democrática, duma solução económica de base cooperativista, duma cultura de base universalista". Talvez pelo seu racionalismo, Sérgio, numa atitude extremamente pragmática e anti-utópica, discorda energicamente da posição de Wells no final de A Chama Imperecível:

[E]specializar o espírito do educando para um esquema imaginário da Sociedade, que talvez não venha a realizar-se nunca, é correr o risco de sacrificar à quimera o indivíduo real e a Sociedade, e exorbitar portanto do professorado, tomando responsabilidades que não lhe competem. O preceito [de] Kant [de que] "não se deve educar para a Sociedade de hoje, mas para uma sociedade melhor, possível no futuro"... não significa pormenorizar um edifício social imaginário e abstracto, e - de fora para dentro - talhar as almas para tal fim. (Sérgio 187-8)

O ensaio de Sérgio é, pois, o primeiro caso dum comentário desenvolvido às ideias e aos ideais Wellsianos. Fica porém o facto de que a "digressão pedagógica" sergiana não foi feita sobre uma tradução portuguesa dum livro de Wells, mas pelo conhecimento pessoal que um intelectual português teve do nosso autor. Até hoje, A Nova Europa/ What Is Coming? é o único texto não ficcional de Wells traduzido em Portugal.

Assim sendo, foi por via brasileira que a maior quantidade de escritos de Wells chegaram à nossa língua e, em certa medida, a Portugal.

3. Muitos anos depois da Livraria Garnier, a Companhia Editora Nacional de São Paulo foi a segunda casa brasileira a publicar obra de 
Wells. Isso deu-se no fim dos anos 30 e princípio dos 40, durante a ditadura de Getúlio Vargas. Monteiro Lobato, co-fundador da editora, o Monteiro Lobato de Urupês e do Sítio do Picapau Amarelo, aparece como o dinâmico promotor da edição pela sua Companhia de The Outline of History em português. A monumental obra, com o título de História Universal, saiu em três volumes a partir de 1939, em tradução de Anísio Teixeira. Foi imensamente popular; as reedições sucederam-se. Foi publicada em Portugal em 1956, e as últimas tiragens, que eu saiba, são de 1974-76 em Lisboa e de 1968 em São Paulo. A mesma editora também deu ao público brasileiro (em tradução de Lobato) a História do Futuro (The Shape of Things To Come) em 1940 e O Destino da Espécie Humana (The Fate of Homo Sapiens) em 1945.

Na mesma altura A Ciência da Vida (The Science of Life) foi publicada no Rio de Janeiro em tradução de Almir de Andrade; a segunda edição é de 1943, mas o livro não se encontra hoje em Portugal. Tão pouco se encontra A Construção do Mundo, o Trabalho, a Riqueza e a Felicidade do Mundo (The Work, Wealth and Happiness of Mankind), em tradução ainda de Monteiro Lobato.

A História Universal, A Ciência da Vida e A Construção do Mundo formam uma trilogia enciclopédica monumental. Porque foram traduzidas no Brasil e não em Portugal? Obras de divulgação de espírito aberto e liberal, foram traduzidas quando os dois países lusófonos estavam sob regime ditatorial. Claro que a ditadura getulista tinha um cunho demagógico e populista bem diferente do salazarismo abeatado e bafiento. Creio que a razão é fundamentalmente económica, e tem que ver com a própria dimensão - das obras e dos países. Edições destas seriam quase inviáveis num país tão pequeno como o nosso - e com tão poucos leitores.

Mas dou ainda outra razão para a ausência do Wells educador e intelectual no nosso país. É que os seus ideais cosmopolitas duma educação científica para um Estado socialista mundial não encontrariam obviamente eco na nossa intelligentsia reaccionária, enquanto a progressista se dividia numa oposição liberal republicana pouco eficaz, e numa marxista, muitíssimo melhor organizada, que se opunha frontalmente ao idealismo utópico de Wells.

As discussões intelectuais mais vivas estavam reservadas para raros eleitos; pensar na apagada e vil tristeza do presente era mais importante que sonhar com as maravilhas do Estado Mundial wellsiano. Sérgio é 
antes uma excepção, e mesmo assim vimos as suas reservas à utopia imaginada por Wells.

4. A edição para Portugal da História Universal foi pretexto para uma brevíssima mas judiciosa apreciação de Wells por um intelectual português. A tarefa de revisão do texto, confiada a Óscar Lopes, foi não só a de purgá-lo de algum brasileirismo mais rebarbativo, mas principalmente reapresentar um texto de história datado de 1932 ao mundo de 1956. A tradução de Anísio Teixeira foi confrontada com o original; o material mais tarde acrescentado por G.P. Wells e Raymond Postgate para a edição póstuma de 1948 foi preterido.

Óscar Lopes fez preceder o primeiro volume por uma "Introdução à Edição Portuguesa", em que apresenta o autor e o põe no contexto da Inglaterra e Europa do seu tempo, basicamente como um burguês progressista. Assinala que a obra começou como uma resposta ou meditação pessoal sobre a história humana após a catástrofe da Grande Guerra. Embora Óscar Lopes avalie e critique Wells duma perspectiva marxista, é o facto de falar em 1956 e com conhecimento do que se passou desde a edição inglesa de 1932 e desde a morte de Wells, em 1946, que marca mais esse seu juízo.

O prefácio ao terceiro volume, com o título "Observações necessárias", apresenta as reservas do intelectual português às conclusões e previsões de Wells, ao mesmo tempo que justifica essas conclusões e profecias dentro da sua época histórica. Aqui se justifica a rejeição da versão actualizada - paradoxalmente, por razões históricas: é que essa edição "omit[e] certas importantes reflexões do autor que dizem respeito à crise desencadeada em 1929 e às perspectivas de preservação da paz internacional."(III, 6). Óscar Lopes quer antes de mais justificar ou explicar as opções ideológicas de Wells (como burguês atravessando a crise dum mundo burguês) e depois como que inseri-lo numa visão de esquerda desse mundo. (Como sabem os que se lembram, não se podia ser explícito nesses tempos; a mensagem passava só aos iniciados).

A feroz concorrência dos vários proteccionismos nacionais e as rivalidades coloniais, diz Óscar Lopes, ajudarão o leitor a compreender

[O] internacionalismo, na verdade um tanto idealista e abstracto, de Wells e algumas das suas opiniões mais discutíveis. Precisamente porque ainda não via nos homens uma capacidade eficaz de evitar a grande Catástrofe 
próxima (a de 1939-45), o idealismo wellsiano só sabia apelar para remédios utópicos. [...] Pretendia então Wells um Estado Federal Mundial, com sacrifício de todas as soberanias nacionais, quando [...] o problema exigido pela natureza humana tem consistido na conquista da soberania política nacional por grande parte dos povos do Mundo, e na conquista da plenitude económica e cultural dessa soberania para quase todos os outros. (III, 6).

Este é o ponto de vista dos anos 50, depois da Revolução Chinesa e do começo das guerras de libertação no Terceiro Mundo, da Indochina à África, quando o "nacionalismo" tinha um sentido diametralmente oposto ao que lhe dava Wells. Na sua peroração Óscar Lopes mais uma vez parece realinhar Wells e a sua ideia de "Progresso" com o progressismo da esquerda comunista, o "frentismo popular" de esquerda e o seu tipo de nacionalismo:

Hoje é fácil criticar várias das suas ingénuas esperanças: a de que surgisse um irresistível movimento federalista mundial; a de que a Segunda Guerra Mundial pudesse ser conjurada pelo simples terror recíproco dos novos poderes destrutivos; a de que a crítica e a luta económica internacional pudesse ser detida por simples acordos monetários internacionais; [....] No entanto, o mais fundo dos grandes ideais wellsianos está hoje mais vigoroso que nunca: pela primeira vez na História, e como o declaram estadistas responsáveis de todas as tendências, são os povos inteiros, e não simples idealistas isolados, que eficazmente não querem a guerra. O Progresso deixou de parecer um produto de espíritos isolados ou de forças inconscientes, para depender, cada vez mais, daquilo que Wells designa como a "comunidade voluntária", autenticamente nacional.

Também a nós, hoje em dia, e da nossa perspectiva superior de cidadãos do século XXI, depois das guerras que entretanto se têm sucedido, é fácil deitar um olhar de esguelha para o optimismo do Óscar Lopes de 1956; a pregação de Wells parece continuar sem dar fruto, e as esperanças de hoje são menores.

5. Para lá disto, o destino português de Wells limita-se a alguma ficção. Em 1945 Alma Simples (Kipps) tinha sido publicado numa boa tradução de Cabral do Nascimento, caso único e singular; mais nada 
apareceu (a não ser a fc do costume). Alguns contos foram incluídos em antologias com títulos como Contos Fantásticos (1943) ou Contos Ingleses Modernos (1945); em 1947 apareceu a antologia Os Melhores Contos de H. G. Wells em Lisboa; em 1956 a Atlântida de Coimbra dedicou-lhe um volume na colecção "Antologia do conto moderno". Estas colecções estão hoje todas esgotadas. E, se The Shape of Things To Come foi traduzida no Brasil, como se disse atrás, em Portugal foi só o guião do filme que chegou, por sinal bem cedo: Coisas Que Hão-de Vir: a Vida Futura, em 1936.

Depois destes sucessos editoriais dos anos dos anos 40 e 50, a presença de Wells em Portugal resume-se a novas ou renovadas edições da mesma fc de sempre. Apareceram traduções de $O$ Homem Invisível em 1966 e de A Guerra dos Mundos em 1968, na Ulisseia; eram edições isoladas, não integradas em qualquer colecção de fc das que apareceram nos anos 50. Em 1979 surge a colecção da Europa América, onde vieram a ser publicadas novas versões de quatro dos cinco clássicos. Em resultado disto podemos contar em Portugal três traduções de The Time Machine entre 1936 e 1992, quatro de The War of the Worlds e seis (!) de The Invisible Man entre 1934 e 2000, duas de The Island of Doctor Moreau em 1988 e 1989. Tudo isto, se é muito agradável, é meramente "passivo": quer apenas dizer que os portugueses foram lendo as mesmas cinco novelas de fc de Wells, mas não houve necessariamente qualquer interacção, já que nunca houve entre nós uma tradição de literatura fantástica ou de ficção científica (não tivemos nenhum Verne, nenhum Čapek), e os nossos poucos praticantes de fc não são propriamente wellsianos (excepção feita a João Barreiros).

Convenhamos que o panorama não é muito animador. Mesmo em todo o espaço lusófono, onde está $o$ Wells, aquele autor multifacetado de tão vasta obra? Até hoje, um livro da importância de A Modern Utopia nunca foi traduzido para português - nem, que eu saiba, teve qualquer reflexo ou influência nos nossos círculos intelectuais. $\mathrm{O}$ mesmo se diga de Men Like Gods, a outra notável utopia wellsiana de 1923. E, para desgosto dos fans, $O$ Alimento dos Deuses nunca voltou aos escaparates, e outras obras menos célebres nunca acharam favor aos olhos dos nossos editores. A Guerra nos Ares e Nos Dias do Cometa, que foram traduzidos no Brasil nos anos 80, não foram importados por nós, nem cá editados. E vou abster-me sequer, por brevidade, de mencionar os textos de ficção realista, ou na fronteira entre o realismo e 
a fantasia, que não foram traduzidos, ou só o foram no Brasil (como Tono-Bungay ou The Holy Terror).

6. Comecei por duas citações: uma de Wells, que nos resume e define: um país simpático, hospitaleiro, e atrasado; muito antes de se ter inventado "o sol da nossa simpatia", Wells descobria os prazeres do nosso clima (e aquela citação foi parar ao Condé Nast Traveler). Quanto à recepção de Wells em Portugal, ela foi evoluindo nos meandros do salazarismo; digamos que ele era um autor tolerado. O próprio salazarismo evoluiu, envelheceu... mas também Wells envelhecia; e mesmo as suas ideias progressivas se foram tornando datadas, com um interesse meramente histórico. Ou académico. O que quer dizer que o nosso autor se poderia ter tornado pelo menos tema de teses, objecto de estudo, de discussão académica; nem isso. Nem ensinado era nas universidades.

A minha outra citação é de Uma Conspiração para o Futuro: o Ensaísmo Político e Educacional em H.G. Wells, uma tese de mestrado apresentada na Universidade Nova em 1993 por Maria Leonor Fernandes. Um trabalho honesto e competente, mesmo se o julgamento crítico expendido pela autora sobre a ficção científica é, mais que discutível, disparatado. Não obstante, a tese é um notável esforço e um exemplo tardio da recepção de Wells em Portugal; obra única, a primeira no seu género. A citação revela, por outro lado, a imagem deixada por Wells entre nós: o autor de fc e o autor da História Universal.

A contribuição da Dr. ${ }^{a}$ Leonor Fernandes tem a meu ver dois significados: ao insistir na ideia de "Wells em Portugal é fc mais a História Universal", revela um preconceito insuspeitado contra um ramo da literatura, mas está afinal a exprimir o sentimento ainda presente no público em geral; a excepcionalidade da sua dissertação manifesta a relativa insignificância do objecto de estudo - ao mesmo tempo que é sinal da vontade de alterar o panorama dos estudos wellsianos em Portugal.

Assim, qualquer comentário a "Wells e Portugal", ou "Wells em Portugal", tem de começar por reconhecer o pouco que há para dizer. A presença de Wells nas nossas livrarias é quando muito ocasional, fortuita; a presença cultural tem de ser vista à luz da história política e cultural do nosso século XX. Por isso volto à pergunta do princípio deste texto: Que tenho eu, enquanto português a dizer sobre ele? E valerá a pena o esforço? 
A resposta passa por uma outra pergunta: eu serei "um wellsiano"? e a resposta tem que ser, humildemente, que sim, sou, ou pelo menos tento sê-lo; e um wellsiano português. O que quer dizer que procuro abordar Wells duma perspectiva portuguesa, num diálogo cultural entre Wells e Portugal. Este tex to é também uma reflexão sobre a minha condição de wellsiano português.

Pouco encontrámos de Wells sobre este jardim da Europa - ou da "nova Europa" - à beira-mar plantado; Portugal, que hoje já não é, como dizia Camões, "quase cume da cabeça de Europa toda", permanece, modestamente, (remansadamente?) marginal, "na periferia do Império". Os conselhos de Wells em 1924 terão sido em parte seguidos, estamos um bocadinho melhor, mas, que diabo, já passaram oitenta anos, malfeito fora!

Creio que todos (portugueses ou não) devemos ainda qualquer coisa às propostas de Wells quanto ao futuro. $\mathrm{O}$ seu projecto de globalização benigna confronta-se hoje com novas formas de imperialismo que podem produzir um verdadeiro Estado Mundial anti-wellsiano. O poder hegemónico dos EUA sob todas as suas formas faz a arrogância dos déspotas das "Wings over the World" no filme Vida Futura parecerem ingénuas e ridículas

Recordemos o papel de Wells na elaboração da Declaração Universal dos Direitos do Homem; recordemos os seus apelos à paz; e, em diálogo com ele, recordemos o apoio de Óscar Lopes, há quase cinquenta anos, às suas ideias mais generosas. Lembro a citação acima, em que o português criticava o internacionalismo de Wells da perspectiva ideológica do internacionalismo pró-russo. Hoje a Rússia está mais uma vez, mas por outras razões, "in the shadows"; o fim da Guerra Fria não foi afinal a vitória da "Guerra para acabar com as guerras", esse slogan entusiástico de Wells em 1914-18; por isso estamos mais uma vez como Wells estava em 1921, em 1946, "the mind at the end of its tether" (o espírito levado aos limites, no limiar do desespero). Como ele próprio disse, "Diabo que vos carregue: eu bem vos avisei" (God damn you all: I told you so.).

Que tem H.G. Wells a ver connosco? Vistes o que eu, português, tinha a dizer sobre ele, e porquê. E ainda acho que valeu a pena o esforço. 


\section{Referências}

Salgado Júnior, António (1973), ‘António Sérgio’ in Coelho, Jacinto do Prado, ed., Dicionário de Literatura, Porto: Figueirinhas, 3rd ed.

SÉrgio, António (1974). 'Divagações pedagógicas a propósito de um livro de Wells', in Ensaios, vol. II, Lisboa: Sá da Costa.

Wells, H. G. (1924). A Year of Prophesying. London: T. Fisher Unwin.

_- (1956). História Universal. Trad. Anísio Teixeira. Revisão para Portugal de Óscar Lopes. Lisboa: Livros do Brasil. 